Research Article

www.jestr.org

\title{
Fracture Characteristics Analysis of Double-layer Rock Plates with Both Ends Fixed Condition
}

\author{
S. R. Wang ${ }^{1,3^{*}}$, D. F. Xu ${ }^{1}$, P. Hagan ${ }^{2}$ and C. L. $\mathrm{Li}^{1}$ \\ ${ }^{I}$ School of Civil Engineering and Mechanics, Yanshan University, Qinhuangdao, 066004- China \\ ${ }^{2}$ School of Mining Engineering, University of New South Wales, Sydney, 2052-Australia \\ ${ }^{3}$ Opening Laboratory for Deep Mine Construction, Henan Polytechnic University, Jiaozuo, 454003-China
}

Received 1 March 2014; Accepted 5 July 2014

\begin{abstract}
In order to research on the fracture and instability characteristics of double-layer rock plates with both ends fixed, the three-dimension computational model of double-layer rock plates under the concentrated load was built by using PFC3D technique (three-dimension particle flow code), and the mechanical parameters of the numerical model were determined based on the physical model tests. The results showed the instability process of the double-layer rock plates had four mechanical response phases: the elastic deformation stage, the brittle fracture of upper thick plate arching stage, two rock-arch bearing stage and two rock-arch failure stage; moreover, with the rock plate particle radius from small to large change, the maximum vertical force of double rock-arch appeared when the particle size was a certain value. The maximum vertical force showed an upward trend with the increase of the rock plate temperature, and in the case of the same thickness the maximum vertical force increased with the increase of the upper rock plate thickness. When the boundary conditions of double-layer rock plates changed from the hinged support to the fixed support, the maximum horizontal force observably decreased, and the maximum vertical force showed small fluctuations and then tended towards stability with the increase of cohesive strength of double-layer rock plates.
\end{abstract}

Keywords: Rock Plate, Hinged Rock-Arch, Instability, Particle Flow Code, Fixed Support Boundary

\section{Introduction}

The roof of mined-out areas is composed of layered rock plates in general. The instability of the layered rock plates is influenced by many factors, such as the rock particle size, the rock-plate boundary conditions and the rock-plate temperature, etc.

Scholars at home and abroad have conducted a lot of research on the stability of the layered rock plates. Z. Gou et al. considered the double-bedded rock slope as the folded beams structure and analyzed the deformation and failure mechanism of the double layered rock slope, discussed the buckling behaviour and the bifurcation characteristic of the laminated beams by using the slab buckling theory and proposed the disaster criterion of the rock structure [1]. Y.S. Liu et al. revealed the anisotropy of mechanical properties for the layered rock, and found that there were internal compression shear failure and shear surface failure based on the uniaxial tests under different bedding angle being measured [2]. C.Y. Bao et al. studied the whole failure process of the layered rock under the uniaxial tension, including surface crack initiation, nucleation, extending, and crack saturation [3]. Y. Pan et al. conducted the analytical analysis of the hard roof deflection of the mined-out areas [4]. Y.X. Wang et al. researched the fracture evolution of the

\footnotetext{
*E-mail address: w_sr88@163.com

ISSN: 1791-2377@ 2014 Kavala Institute of Technology. All rights reserved.
}

brittle rock plate under the impact load [5]. S.R. Wang et al. conducted the loading test of the single and double-layer rock plates using the patented loading device, and proved that there were four mechanical response phases in the loaddisplacement curve [6], [7]. G.L. He et al. presented the instability mechanism of coal pillar-roof system by using the plate mechanics and the nonlinear dynamics theory, and put forward the mathematical criterion and mechanical condition of the system instability [8]. Y.L. Zhao et al. analyzed the safety stability of the goaf roof based on the catastrophe theory [9]. J.A. Wang et al. researched the rheological failure characteristics of the pillar-roof in the mined-out areas [10]. P.P. Nomiko etc. analyzed the instability size effect of the multilayered rock beam structural [11]. M. Cravero et al. discussed the flexure instability characteristics of the gneiss plate by using linear elastic fracture mechanics and finite element method [12], and the related studies [13], [14], etc.

In summary, the above mentioned research usually simplified rock plate as elastic rock beam or elastic thin plate based on the continuum mechanics, therefore the theory, method and content of the research needed to be further developed and deepened. So in the paper, using selfprepared three-dimension particle flow code $\left(\mathrm{PFC}^{3 \mathrm{D}}\right)$, the numerical loading tests of double-layer rock plates were performed under the concentrated load, and the sensitive factors of fracture instability of double-layer rock plates were analyzed. The research results would provide reference 
and guiding significance for the stability evaluation on the roof of the mined-out areas.

\section{Numerical Experiment of Double-layer Rock Plates}

\subsection{Micro-parameters of the rock plate}

$\mathrm{PFC}^{3 \mathrm{D}}$ models the movement and interaction of spherical particles as described by Cundall and Strack (1979). PFC ${ }^{3 \mathrm{D}}$ is also able to model a brittle solid by bonding every particle to its neighbor, and is capable of fracturing when bonds break in a progressive manner.

(1) Basic assumptions in $\mathrm{PFC}^{3 \mathrm{D}}$

$\mathrm{PFC}^{3 \mathrm{D}}$ provides the following assumptions:

a) The particles are treated as rigid bodies.

b) The contacts occur over a small area (i.e., at a point).

c) Behavior at the contacts uses a soft-contact approach wherein the rigid particles are allowed to overlap one another at contact points.

d) The magnitude of the overlap is related to the contact force via the force displacement law, and all overlaps are small in relation to particle sizes.

e) Bonds can exist at contacts between particles.

f) All particles are spherical; however, the clump logic supports the creation of super-particles of arbitrary shape.

(2) Main models in PFC ${ }^{3 \mathrm{D}}$

The force-displacement law relates the relative displacement between two entities at a contact to the contact force acting on the entities. Particles interact with other particles, and with walls, through the forces that develop at their contacts. The constitutive model acting at a particular contact in PFC ${ }^{3 \mathrm{D}}$ consists of three parts: a stiffness model, a slip model, and a bonding model.

\section{a) Contact-stiffness model}

The contact force vector $F_{i}$ can be resolved into normal and shear components with respect to the contact plane as shown in Fig.1.

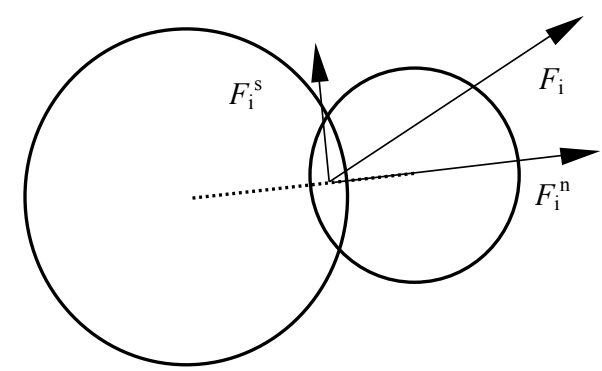

Fig.1 Contact force vector description

The normal contact force $F_{i}^{n}$ is calculated by

$F_{i}^{n}=k^{n} U_{i}^{n}$

where

$k^{n}$ is the normal stiffness at the contact

$U_{i}^{n}$ is the normal displacement at the contact.

The shear contact force $F_{i}^{s}$ is calculated by

$F_{i}^{s}=k^{s} U_{i}^{s}$ where

$k^{s}$ is the shear stiffness

$U_{i}^{S}$ is the shear displacement at the contact.

b) The slip model

The slip model provides no normal strength in tension and allows slip to occur by limiting the shear force.

The contact is checked for slip conditions by calculating the maximum allowable shear contact force.

$F_{\max }^{s}=\mu\left|F_{i}^{n}\right|$

where

$F_{\max }^{s}$ is the maximum allowable shear contact force.

$\mu$ is taken to be the minimum friction coefficient of the two contacting entities.

If shear force $F^{s}>F_{\max }^{s}$, then slip is allowed to occur.

c) Bonding model

$\mathrm{PFC}^{3 \mathrm{D}}$ allows particles to be bonded together at contacts through a contact-bond model or a parallel-bond model. Both bonds can be envisioned as a kind of glue joining the two particles.

If the magnitude of the tensile normal contact force equals or exceeds the normal contact bond strength, the bond breaks, and both the normal and shear contact forces are set to zero. If the magnitude of the shear contact force equals or exceeds the shear contact bond strength, the bond breaks, but the contact forces are not altered, provided that the shear force does not exceed the friction limit as shown in Fig.2.

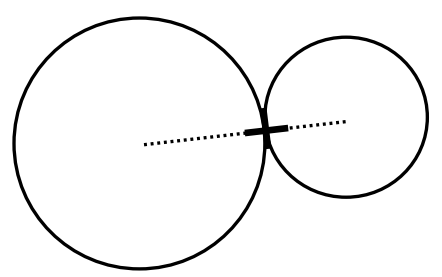

Fig.2 Contact-bond model description

Parallel bonds can transmit both forces and moments between particles, while contact bonds can only transmit forces acting at the contact point. Thus, parallel bonds may contribute to the resultant force and moment acting on the two bonded particles as shown in Fig.3.

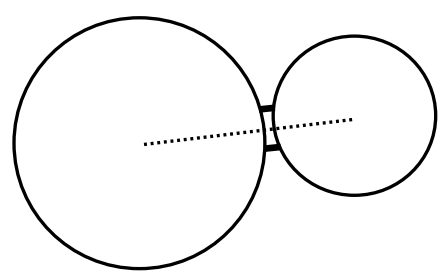

Fig.3 Parallel-bond model description

Relative motion at the contact causes a force and a moment acting on the two bonded particles. If either of these maximum values exceeds its corresponding bond strength, the parallel bond breaks. 


\section{/Journal of Engineering Science and Technology Review 7 (2) (2014) 60 - 65}

\subsection{Micro-parameters of the Rock Plates}

Before building the computational model, the microparameters of the rock plate should be determined. By repeatedly adjusting the micro-parameters of the model until the numerical experiment results were consistent with the physical test results [6]. Fig. 4 was the result of double-layer rock plates with both ends hinged under the concentrated load which was conducted at school of mining engineering, university of New South Wales, Australia.

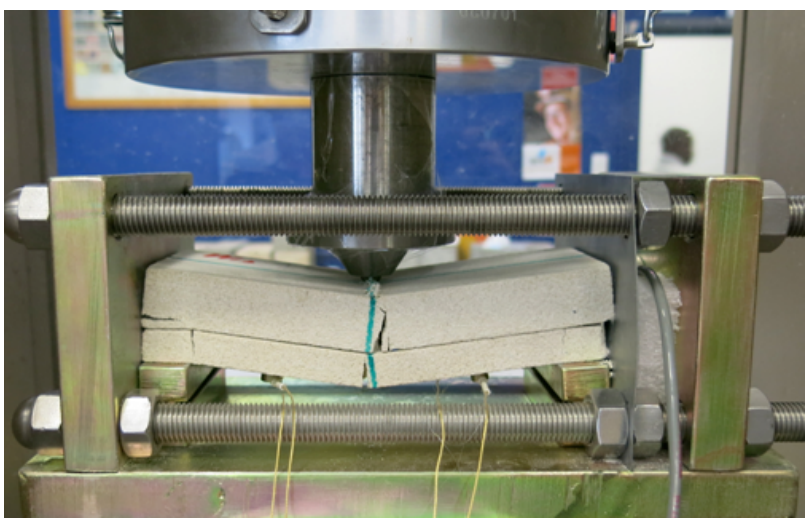

Fig. 4. The laboratory test of double-layer rock plates under the concentrated load

The micro-parameters required to be adjusted were as follows: $\rho$ is ball density, $R_{\min }$ is minimum ball radius, $R_{-}$ratio is ball size ratio, $\bar{\lambda}$ is parallel-bond radius multiplier, $E_{c}$ is ball-ball contact modulus, $\bar{E}_{c}$ is parallelbond modulus, $k_{n} / k_{s}$ is ball stiffness ratio, $\overline{k_{n}} / \overline{k_{s}}$ is parallel-bond stiffness ratio, $\mu$ is ball friction coefficient, $\bar{\sigma}_{c}$ is parallel-bond normal strength, and $\bar{\tau}_{c}$ is parallelbond shear strength. The micro-parameters required to be adjusted were listed in the Table 1 .

Table 1 Micro-parameters of the rock plates in $\mathrm{PFC}^{3 \mathrm{D}}$

\begin{tabular}{ccccc}
\hline$\rho\left(\mathrm{kg} / \mathrm{m}^{3}\right)$ & $R_{\min }(\mathrm{mm})$ & $R_{-}$ratio & $\mu$ & $\bar{\lambda}$ \\
\hline 2650 & 1.2 & 1.66 & 0.5 & 1.0 \\
\hline $\bar{E}_{c}(\mathrm{GPa})$ & $k_{n} / k_{s}$ & $\bar{k}_{n} / \bar{k}_{s}$ & $\bar{\sigma}_{c}(\mathrm{MPa})$ & $\bar{\tau}_{c}(\mathrm{MPa})$ \\
\hline 2.8 & 1.8 & 1.8 & 1.6 & 1.6 \\
\hline
\end{tabular}

\subsection{Building the Computational Model}

Taking the upper thick plate and the lower thin plate as an example, in order to show how to build the numerical calculation model, the special idea of the model was as follows:

First of all, the model size of the rock plate was $190 \mathrm{~mm}$ long, $75 \mathrm{~mm}$ wide and $38 \mathrm{~mm}$ high, and the model was generated by the radius expansion method (Fig. 5a). Then, the level joint plane was set in the double-layer rock plates, and the upper thickness was $24 \mathrm{~mm}$ and the lower thickness was $14 \mathrm{~mm}$ (Fig. 5b). After removing the wall around the rock plate, on the top of the upper plate a square wall was built as the concentrated load whose side length was 1.0 $\mathrm{mm}$, and meanwhile the two cylinder walls were respectively placed under the right and left of the bottom of the lower plate as the supporting base (Fig. 5c).

The loading rate was set to $0.01 \mathrm{~m} / \mathrm{s}$. During the loading process of the rock plates, in order to study the crack growth, the appearing cracks were monitored in real time. The red cracks represented the tensile fracture, and the black ones represented the shear fracture.

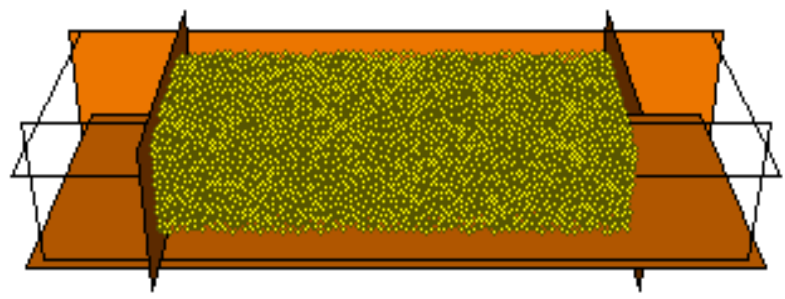

a) The initial model

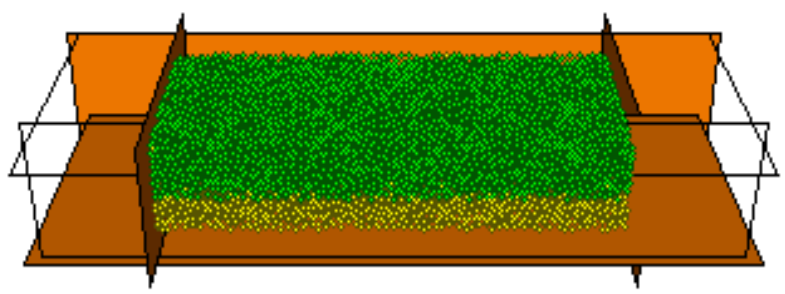

b) The generated double-layer plates

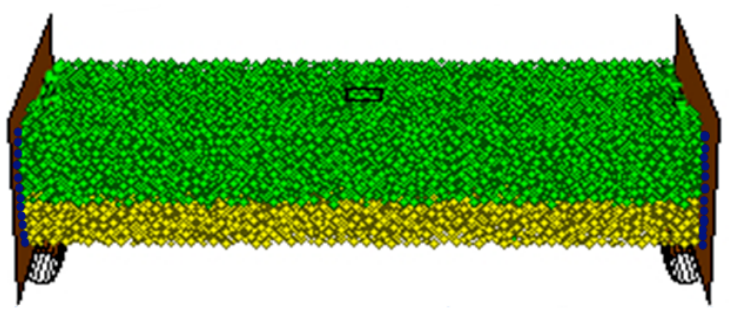

c) The computational model

Fig. 5 Building the computational model

2.4 Fracture Characteristics of Double-layer Rock Plates As shown in Fig. 6, under the concentrated load, the doublelayer rock plates with the fixed boundary condition had four mechanical response phases: the elastic deformation stage, the brittle fracture of upper thick plate arching stage, two rock-arch bearing stage and two rock-arch failure stage. In the elastic stage in Fig. 6a, the double-layer rock plates produced the small deformation and there was no crack appearing at the moment. At the brittle fracture stage in Fig. $6 \mathrm{~b}$, the upper thick plate showed a transfixion crack and formed a hinged rock-arch structure, while there was shear and tension cracks appearing on both ends of the lower thin plate. With the vertical force increase, the crack number of upper plate increased, and the fracture zone produced in the central position of the lower plate, then there formed two hinged rock-arch structures, and the double-layer rock plates stepped into two rock-arch bearing stage in Fig. 6c. At this moment, the shear and tension cracks formed on the junction plane of the upper and the lower plate, but the tension cracks were major. At two rock-arch failure stage in Fig. 6d, the larger deformation appeared and the cracks significantly increased. 


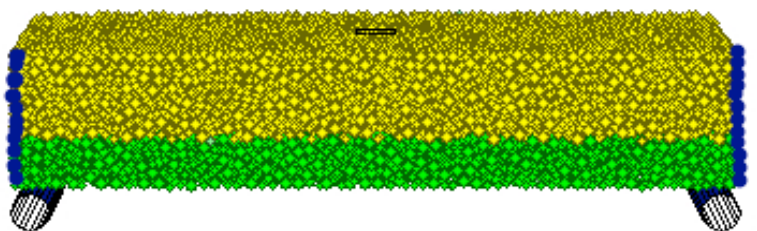

a) The elastic deformation stage

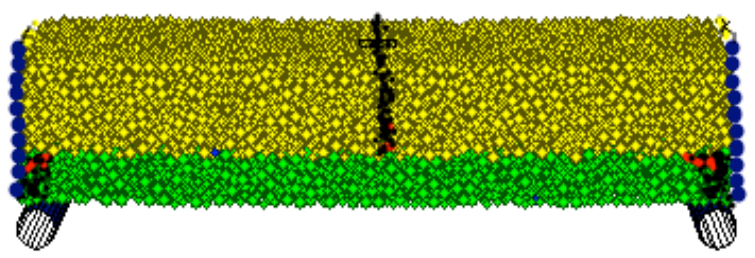

b) The upper thick plate arching stage

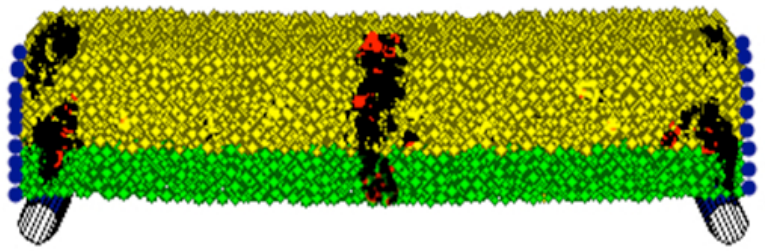

c) Two rock-arch bearing stage

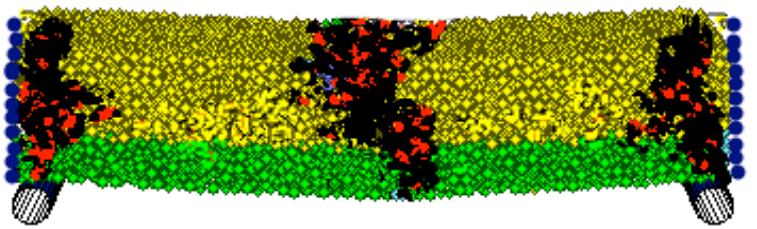

d) Two rock-arch failure stage

Fig. 6 The deformation and failure process of double-layer rock plates

As shown in Fig. 7, under the concentrated load, the relation curves of double-layer rock plates which were about the vertical force, the crack number and the displacement could be divided into four stages: the elastic deformation stage A was corresponding to the stage with the displacement from $0 \mathrm{~mm}$ to $1.8 \mathrm{~mm}$, and in stage A with the increase of vertical displacement the vertical force curve presented the linear growth trend, but the crack number was zero. The brittle fracture stage B was corresponding to the stage with the displacement from $1.8 \mathrm{~mm}$ to $4.3 \mathrm{~mm}$, and in stage B the vertical displacement continued to increase and the vertical force curve and the crack number curve showed a rising trend, at the moment the tension crack was major, the growth of shear crack was not obvious. The rock-arch structure bearing stage $\mathrm{C}$ was corresponding to the stage with the displacement from $4.3 \mathrm{~mm}$ to $7.2 \mathrm{~mm}$. In stage $\mathrm{C} \mathrm{a}$ through fractured zone appeared on the double-layer rock plates, formed two hinged rock-arch structures, the vertical force presented a step downtrend, and both the tension cracks and shear cracks had an obvious growth trend. The instability stage $\mathrm{D}$ was the stage with the displacement exceeding $7.2 \mathrm{~mm}$, and in stage D the vertical force of the double-layer rock plates significantly declined and the cracks number of tension and shear maintained the stability basically.
3. Sensitive Factors Analysis of Instability of Doublelayer Rock Plates

\subsection{Analysis of Rock Particle Radius Changing}

As shown in Fig. 8, under the boundary condition of both ends fixed and both sides free, the vertical force curves went up first and then down. The influence factors of the result were mainly the number of particles and the size of particles in particles aggregate. When the particle radius of rock plates increased from $1.0 \mathrm{~mm}$ to $1.4 \mathrm{~mm}$, the increase of particles bond energy held a leading post, therefore, the vertical force of rock plates showed a trend of gradual increase; When the particle radius increased from $1.4 \mathrm{~mm}$ to $1.8 \mathrm{~mm}$, the increase of particles bond energy were not obvious, and the number of particles significantly decreased that resulted in the decrease of vertical force.

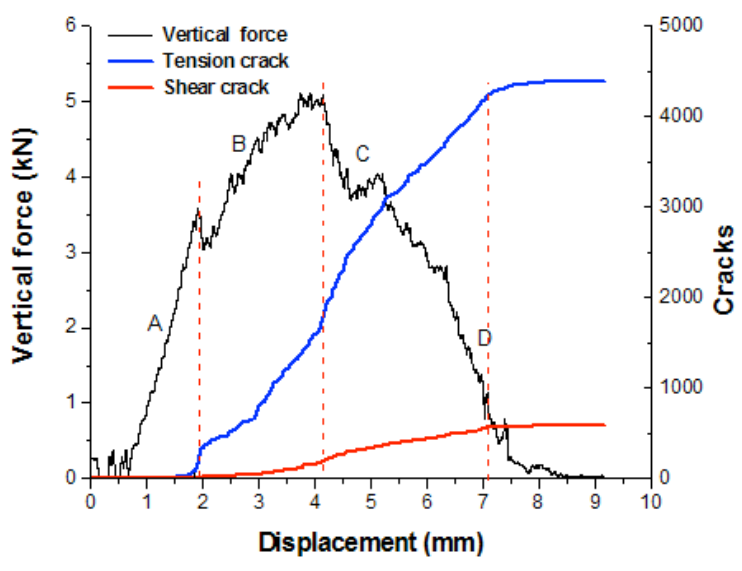

Fig.7 The vertical force-crack number-displacement relation curves

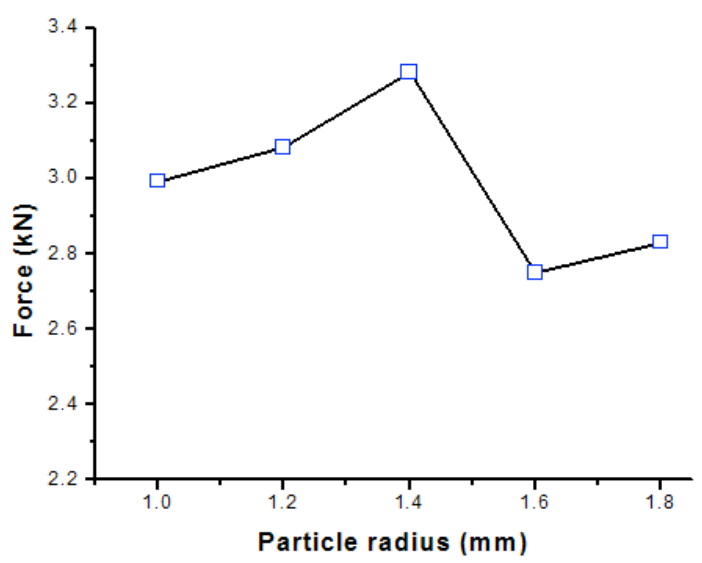

Fig.8 The maximum vertical force-particle radius relation curve

\subsection{Temperature Effect Analysis of Rock Plates}

As shown in Fig. 9, under the boundary condition of both ends fixed and both sides free, with the temperature increased from $0{ }^{\circ} \mathrm{C}, 200{ }^{\circ} \mathrm{C}, 400{ }^{\circ} \mathrm{C}, 600{ }^{\circ} \mathrm{C}$ to $800{ }^{\circ} \mathrm{C}$, the maximum vertical force of rock plates presented an $\mathrm{S}$ shaped curve rising trend. As the temperature varied from 0 ${ }^{\circ} \mathrm{C}$ to $400{ }^{\circ} \mathrm{C}$, the maximum vertical force was slow growth. While the temperature varied from $400{ }^{\circ} \mathrm{C}$ to $800{ }^{\circ} \mathrm{C}$, the maximum vertical force was growing fast. That was due to the temperature rise of rock plates, the particle expansion of rock plates led to enhance particle interaction, thus the maximum vertical force of resisting deformation and failure of double-layer rock plates became larger. 
S. R. Wang, D. F. Xu, P. Hagan and C. L. Li

/Journal of Engineering Science and Technology Review 7 (2) (2014) 60-65

\subsection{Geometry Size Effect Analysis of Rock Plates}

As shown in Fig. 10, when the total thickness of rock plates was a certain fixed value $38 \mathrm{~mm}$, with the thickness of the lower and the upper rock plate changing, the maximum vertical force of double-layer rock plates produced a significant change. According to the order of the maximum vertical force from small to large, the combination forms were in turn the upper thin $14 \mathrm{~mm}$ and the lower thick plates $24 \mathrm{~mm}$, the same thickness $19 \mathrm{~mm}$ of double-layer plates, the upper thick $24 \mathrm{~mm}$ and the lower thin $14 \mathrm{~mm}$ plates, the whole piece of thick plate $38 \mathrm{~mm}$. With the combination forms of rock plates changing, the maximum vertical force of double-layer rock plates increased as shown in Fig. 10.

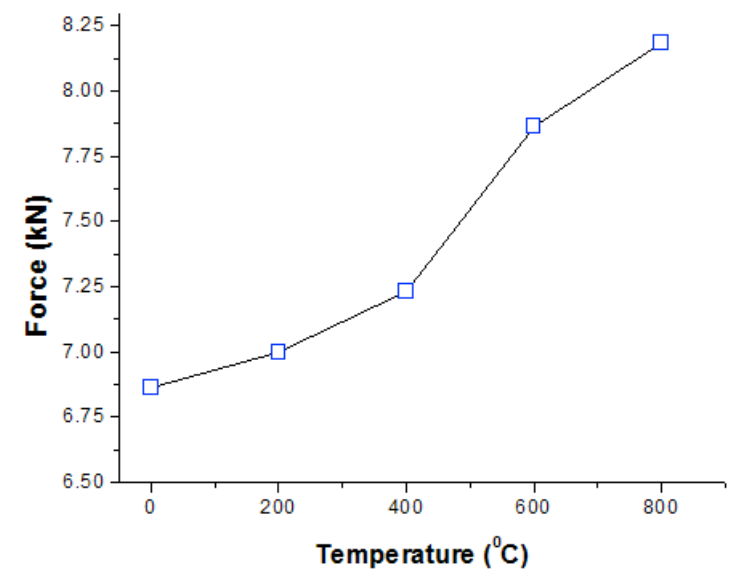

Fig.9 The maximum vertical force-temperature relation curve

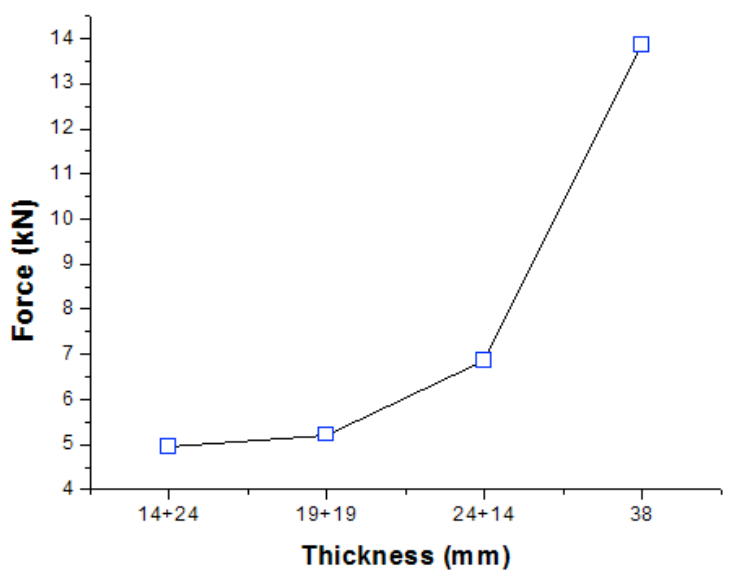

Fig.10 The maximum vertical force-rock plates thickness relation curve

\subsection{Analysis of Boundary Conditions Change Effect}

As shown in Fig. 11, taking the combination form of the upper thick and the lower thin plates as an example, under the condition of double-layer rock plates on both short sides free, the rest both sides were in turn two hinged rock plates in Fig. 11a, the lower fixed and the upper hinged in Fig. $11 \mathrm{~b}$, the upper fixed and the lower hinged in Fig. 11c, and the two plates fixed in Fig. 11d. As shown in Fig. 12, with the boundary conditions changing, the maximum vertical force of the rock plates did not change significantly, while the maximum horizontal force significantly decreased as the articulated degree increased.

\subsection{Cohesive Strength Effect Between Two Rock Plates}

As shown in Fig. 13, with the cohesive strength of the layer between double-layer rock plates increasing from $0 \mathrm{MPa}, 0.5$ $\mathrm{MPa}, 1.0 \mathrm{MPa}, 1.5 \mathrm{MPa}, 2.0 \mathrm{MPa}, 5.0 \mathrm{MPa}, 7.5 \mathrm{MPa}$ to 10 $\mathrm{MPa}$, the maximum vertical force curve appeared first decrease and then increase, finally tended to be stable. As the cohesive strength varied from $0 \mathrm{MPa}$ to $1.0 \mathrm{MPa}$, the maximum vertical force showed increase initially and decrease afterwards, showing that there the peak value existed in the curve; as the cohesive strength varied from 1.0 MPa to $10 \mathrm{MPa}$, the interaction between the upper and the lower rock plates gradually increased, the maximum vertical force gradually increased and then tended to a stable value, and the amplitude of fluctuation was limited.

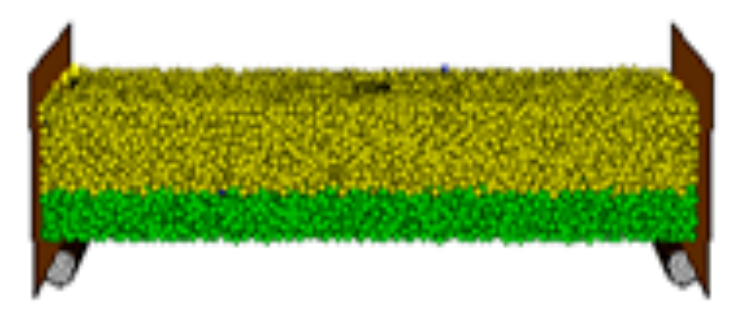

a) Two hinged rock plates

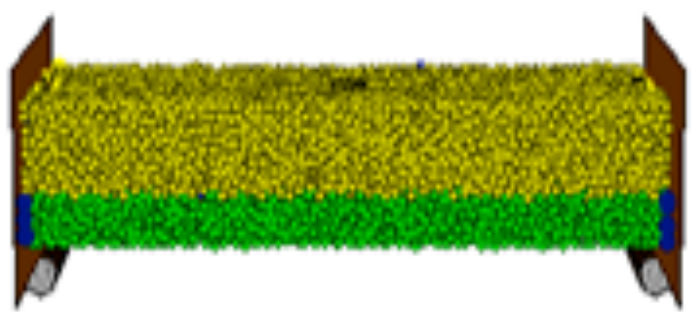

b) The lower fixed and the upper hinged plates

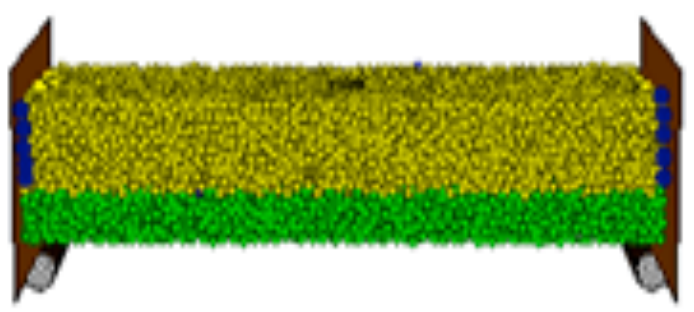

c) The upper fixed and the lower hinged plates

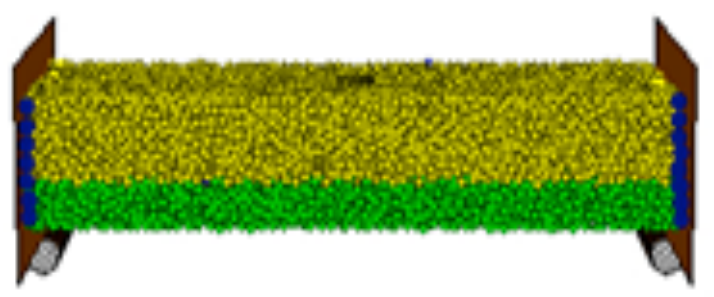

d) Two rock plates fixed

Fig.11 The boundary conditions change on both long sides of the rock plates 


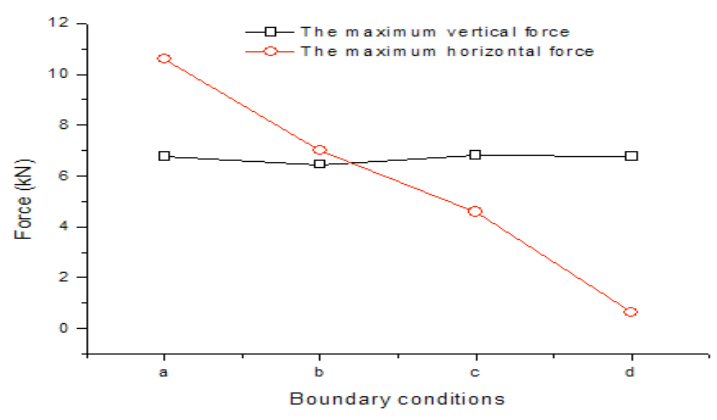

Fig.12 The vertical - horizontal force -the boundary conditions effect

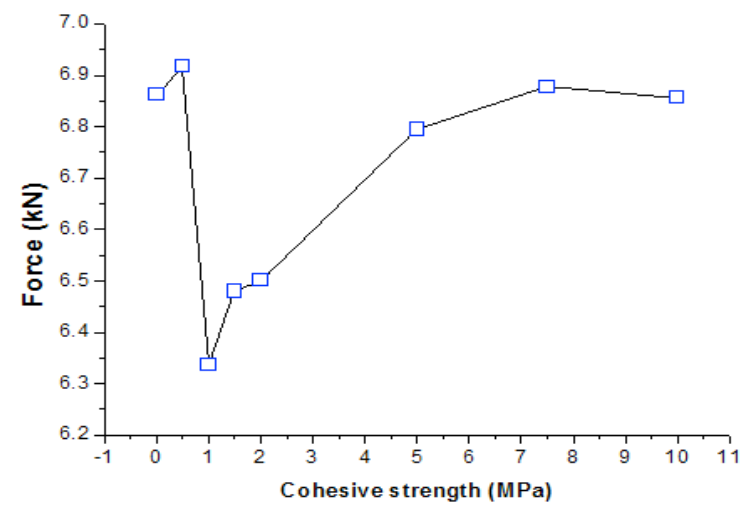

Fig.13 The maximum vertical force- layer cohesive strength between rock plates

\section{Conclusions}

The fracture nonlinear mechanical behavior of double layerhinged rock arch structures could be revealed by using $\mathrm{PFC}^{3 \mathrm{D}}$ technique. The number of tension and shear cracks, crack initiation sequence, and crack propagation process could be visualized through particle flow code.

The sensitivity tests of influent factors on the limiting load being loaded on the double-layer rock plates were carried out, the factors affecting the maximum vertical force from large to small were rock plate thickness, rock plate temperature, rock plate particle size, layer cohesive strength between two plates and the boundary conditions change, the maximum horizontal force varied obviously depending on the boundary conditions change of two rock plates.

The research results were of great significance in evaluating on the roof stability of the mined-out areas.

\section{Acknowledgements}

This work was financially supported by the National Natural Science Foundation of China (51074140; 51310105020), the Natural Science Foundation of Hebei Province of China (E2014203012) and Program for Taihang Scholars, all these are gratefully acknowledged.

\section{References}

1. Gou Z., "Research on buckling behavior of bedding slope with bilayer rocks", Journal of Shandong University of Science and Technology (Natural Science), 27 (6), 2008, pp. 21-23. (in Chinese)

2. Liu Y.-S., Fu H.-L., Wu Y.-M., Rao J.-Y., Yin Q. and Yuan W., "Experimental study of elastic parameters and compressive strength for transversely isotropic rocks", Journal of Central South University (Science and Technology), 44 (8), 2013, pp. 3398-3404. (in Chinese)

3. Bao C.-Y., Tang C.-A., Tang S.-B., Cai M. and Yu Q., "Research on formation mode and mechanism of layered rock surface fractures under uniaxial tension load", Chinese Journal of Rock Mechanics and Engineering, 32 (3), 2013, pp. 474-482. (in Chinese)

4. Pan Y., Gu S.-T. and Qi Y.-S., "Analytic solution of tight roof" bending moment, deflection and shear force under advanced supercharger load and supporting resistance before first weighting", Chinese Journal of Rock Mechanics and Engineering, 32 (8), 2013, pp. 1544-1553. (in Chinese)

5. Wang Y.-X., Cao P. and Yin T.-B., "Simulation research for impact damage fracture evolution of brittle rock plate under impact loading", Journal of Sichuan University (Engineering Science Edition), 43 (6), 2011, pp. 85-90. (in Chinese)

6. Wang S.-R., Hagan P. and Cheng Y., "Experimental research on the instability characteristics of double-layer rock plates based on MTS-AE system", Applied Mathematics \& Information Sciences, 7 (1L), 2013, pp. 339-345.

7. Wang S.-R., Hagan P., Cheng Y. and Wang H., "Experimental research on fracture hinged arching process and instability characteristics for rock plates", Chinese Journal of Rock Mechanics and Engineering, 31 (8), 2012, pp. 1674-1679. (in Chinese)
8. He G.-L., Li D.-C., Zhai Z.-W. and Tang G.-Y., "Analysis of instability of coal pillar and stiff roof system", Journal of China Coal Society, 32 (9), 2007, pp. 897-901

9. Zhao Y.-L., Wu Q.-H., Wang W.-J., Wan W. and Zhao F.-J., "Strength reduction method to study stability of goaf overlapping roof based on catastrophe theory", Chinese Journal of Rock Mechanics and Engineering, 29 (7), 2010, pp. 1424-1434. (in Chinese)

10. Wang J.-A., Li D.-Z. and Shang X.-C., "Mechanics analysis on creep fracture of strong roof strata above mined-out area", Journal of University of Science and Technology Beijing, 33 (2), 2011, pp. 142-148. (in Chinese)

11. Nomikos P.P., Sofianos A.I. and Tsoutrelis C.E., "Structural response of vertically multi-jointed roof rock beams", International Journal of Rock Mechanics and Mining Sciences, 39 (1), 2002, pp. 79-94.

12. Cravero M. and Iabichino G., "Analysis of the flexural failure of an overhanging rock slab", International Journal of Rock Mechanics and Mining Sciences, $41\left(\mathrm{~S}_{1}\right), 2004$, pp. 241-246.

13. Kang H.-Z., Jia K.-W. and Ma W.-H., "Experimental study on compressive strength and elastic modulus of ferrous mill tailing concrete", Journal of Engineering Science and Technology Review, $6(5), 2013$, pp. 123-128

14. Mi G.-F., Li C.-Y. and Gao Z., "Application of numerical simulation on cast-steel toothed plate", Engineering Review, 34 (1), 2014, pp. 1-6. 